\title{
Let's not ignore when the patient snores in clinic: an alarming call for oral health care professionals
}

\author{
Chidambaram Ramasamy', Subrmani Parusuraman² \\ 'Department of Prosthodontics, Faculty of Dentistry, AIMST University, Bedong, Kedah Darul Aman, MALAYSIA. \\ 'Unit of Pharmacology, Faculty of Pharmacy, AIMST University, Bedong, Kedah Darul Aman, MALAYSIA. \\ E-mail: dr.ramasamyc@gmail.com \\ DOI: 10.5530/jyp.2017.9.1
}

Sleeping well is a fundamental right to any individual to maintain good physical and mental health. If that is so, should we mind when a patient dozes off in the medical units or dental reception? In layman's terms inadequate sleep is the likely reason but as responsible oral health care professionals interpreting in terms of Excessive Daytime Sleepiness (EDS), is a sensible approach. EDS is not a disease rather it's a serious symptom linked with various disorders. It's alarming that around 42 million people are victims of sleeping disorder in United States. ${ }^{1}$ Potential causes include Obstructive Sleep Apnea (OSA), insomnia, narcolepsy, sedatives, psychiatric disorders and restless leg syndrome. OSA is claimed as the most common reason of EDS. OSA candidate present difficulty in breathing owing to defective pharyngeal dilator muscles that eventually obstruct the upper airways (UA). Blockage of airflow enforces them to wake up in night and wherein the patients are not aware of the constant arousals. Irregularity in breathing and deprived sleep leads them to be categorized as 'sleepy patients'. Press reports have revealed that people in Malaysia are able to afford only 6.4 hours of sleep per $24 \mathrm{~h}$, which considerably affects their routine activity. ${ }^{2}$ It is sad to know that $10-20 \%$ of male adults and 7-9\% of children of Malaysian population is victims of sleeping disorder. ${ }^{3}$ Though commonly seen in the middle-aged adults and obese candidates, mutually the male and female genders are affected. Continuous Positive Airway Pressure (CPAP) serves as the gold standard in treating severe OSA patients. Meanwhile poor patient compliance compromises the effectiveness and lead to search for other adjuncts like custom made oral appliances. It is recommended as the best alternative in mild-moderate sufferers, wherein the mandible is held in a forward position to enhance the airflow. The introduction of oral devices by American Academy of Sleep Medicine (AASM) has attracted the dental professionals and become a special area of interest. ${ }^{4}$ Dental experts though proficient in treating OSA patients are not in a position to diagnose them at incipient stage. If undiagnosed, these individuals are susceptible to life-threatening conditions like cardiovascular morbidity, road-traffic crashes and short life-span. ${ }^{5}$

So, how to diagnose a sleepy patient? Numerous investigations like polysomnography, endoscopy/laryngoscopy, pharyngometry, and_computed tomography (CT) or magnetic resonance imaging (MRI) are recommended by the medical experts. Honestly, the general dentists bound to the out-patient practice are not able to reap the advantages. Fortunately medical literature supports us with meagre intra-oral findings like tooth wear, macroglossia, large tonsils that are commonly seen in sleep disorders. ${ }^{6,7}$ But in general dental practice, the associated intra-oral findings could be misinterpreted or ignored. For instance, the aetiology of tooth wear is mutlifactorial and nocturnal grinding is one among them that prompts the dentists to categorize the sufferers as bruxism patients rather than OSA. Because the dental education instructs to contemplate as bruxism when tooth wear is identified. Symmetry of the dento-facial morphology (elongated face, micrognathia, retrognathia) does help the dentist to identify the sufferers if at all the practitioner gives importance to extra-oral features like an orthodontist. Considering general dental practice, the associated extra-oral findings could be missed or interpreted with anomalies. It is unfair to blame the general dental practitioners and oral experts for the unacquainted information.

Henceforth, a confirmative clinical investigation is mandatory in order to avoid differential diagnosis. Lateral cephalometry, a conventional method (patient upright position) widely used by orthodontists to image the craniofacial complex mutually aids in the evaluation of UA. Interestingly, recent research reveals that images recorded in supine position provided more information on the cranio-facial features and associated soft tissue structures (soft palate, uvula, palate) that retain importance in pathogenesis of OSA. ${ }^{8}$ Despite being a pet tool of orthodontists, all oral health-care professionals could avail cephalometry considering its economic factor and reduced radiation exposure. Conjointly as a preventive \supportive measure the World Association of Sleep Medicine has been instrumental in conducting World Sleep Day annually to guide the medical team of OSA and raise awareness among the public. ${ }^{9}$ Next time, when a patient is (asleep) unconscious in clinic, let's be conscious to diagnose early and refer to the sleep specialist.

\section{REFERENCES}

1. Sleep apnoea statistics and facts 2016. Available from: http://www.bergerhenryent.com/sleep-apnea-statistics-2016/. Last accessed on 21/06/2016.

2. Consumer association of Penang. Malaysians don't sleep enough and suffer health problems. [Internet].Penang, Malaysia: [updated 2015 Feb 5]. Available from: http://www.consumer.org.my/index.php/health/lifestyle/828-malaysiansdont-sleep-enough-and-suffer-health-problems.

3. Zamzil Amin Asha'ari. Dangers of obstructive sleep apnoea. New Straits Times Online. Available from: http://www.nst.com.my/news/2015/09/dangers-obstructive-sleep-apnea. Last accessed on 02/05/2016.

4. Steven CS, Leslie CD, Fernanda RA, Kathleen MB, Norman TB, et al. Definition of an effective oral appliance for the treatment of obstructive sleep apnea and snoring: A report of the American academy of dental sleep medicine. J of Dental Sleep Med. 2014;1(1):39-50.

5. Ramasamy C. Examination of obstructive sleep apnea at regular intervals: an essential requirement for drivers in Malaysia. Malay J Med Sci. 2017 Epub. Ahead of print.

6. Al-Jewair TS, Nazir MA, Al-Masoud NN, Alqahtani ND. Prevalence and risks of habitual snoring and obstructive sleep apnea symptoms in adult dental patients. Saudi Med J. 2016;37(2):183-90. https://doi.org/10.15537/smj.2016.2.12852

This is an open access article distributed under the terms of the Creative Commons Attribution-NonCommercial-ShareAlike 4.0 License, which allows others to remix, tweak, and build upon the work non-commercially, as long as the author is credited and the new creations are licensed under the identical terms. 
PMid:26837402 PMCid:PMC4800918.

7. Nimma VL, Harshavardhan T, Deepika M, Shakuntala S, Nithya N, Manasa P. Importance of cephalographs in diagnosis of patients with sleep apnea. Contemp Clin Dent. 2015:6(Suppl 1):221-6. https://doi.org/10.4103/0976-237X.166827 PMid:26604577 PMCid:PMC4632226.
8. Antonio Culebras, Liborio Parrino. World sleep day. Available from: http://worldsleepday.org/get-involved/2016-slogan. Last accessed on 30/07/2016.

9. Durán-Cantolla J, Alkhraisat MH, Martínez-Null C, Aguirre JJ, Guinea ER, Anitua E. Frequency of obstructive sleep apnea syndrome in dental patients with tooth wear. J Clin Sleep Med. 2015;11(4):445-50. https://doi.org/10.5664/jcsm.4602.

Article History: Submission Date: 08-06-16; Revision Date: 30-07-16; Accepted Date: 07-08-16.

Cite this article: Ramasamy C, Parusuraman S. Let's not ignore when the patient snores in clinic: an alarming call for oral health care professionals. J Young Pharm. 2017;9(1):1-2. 